\title{
AC 2010-1490: THE UNIVERSITY POWER PLANT: A READILY ACCESSIBLE REMOTE LEARNING PLATFORM
}

\section{F. Carl Knopf, Louisiana State University}

Kerry Dooley, Louisiana State University, Baton Rouge 


\title{
The University Power Plant: A Readily Accessible Remote Learning Platform
}

\begin{abstract}
$\underline{\text { Abstract }}$
Combined heat and power (CHP) or cogeneration is critical to the economic viability of many industries, including fuels, chemicals, plastics, paper, and ferrous and nonferrous metals. U.S. investment in new CHP is expected to remain $>\$ 10$ billion/yr, and there are many ongoing CHP systems that can realize substantial dollar savings through optimal energy management schemes.

CHP systems provide an excellent platform for students to study thermodynamics, certain unit operations and process design principals, optimization, data reconciliation, and emissions control. Even better, many Universities have ready (albeit remote) access to such a system on their own campus. At LSU, we are opening our newer (commissioned 2005, $20 \mathrm{MW}, \$ 20 \mathrm{MM}$ ) cogeneration system to the world of engineering education through real-time data delivery using formats which can communicate with virtually any control/data acquisition system and then broadcast compressed data via the net. Easy to use (from Excel) education modules have been developed which make use of these data to teach the above-mentioned topics in classes ranging from introductory Sophomore-level to capstone design.
\end{abstract}

\section{$\underline{\text { Curriculum Enhancement through Cogeneration Educational Modules }}$}

We have developed educational modules based on cogeneration that can be integrated throughout the Chemical Engineering and Mechanical Engineering curricula. The cogeneration system is an ideal means of establishing an energy thread in Engineering curricula, in both lecture and lab courses. The six currently available modules include: for the Sophomore or Junior Years, ideal gas performance (IGP); for the Junior Year data reconciliation (DR) and realgas performance (RGP); for the Senior Year numerical modeling of heat transfer (HT), levelized economics (LE), and cogeneration system optimal design (OD). For each module we developed a 15-20 page manual including background and problem details. The manuals, which are posted on our web site web site www.cogened.lsu.edu, also serve as the basis for a one hour lecture on each topic.

Sophomore / Junior Years: For the first thermodynamics course in ChE and ME we provide a module (IGP) which uses ideal gas calculations to predict cogeneration performance, including the air cooler, air compressor, combustion chamber, turbines, and heat recovery steam generator (HRSG). This module naturally follows the traditional heat and power discussion of first thermodynamics courses. The performance of the LSU system, as determined from ideal gas calculations, is compared to actual data and simulation results from commercial packages including GateCycle and IPSEpro. Students are encouraged to visit the web site www.cogened.lsu.edu to obtain their own real time data for the cogeneration system. The calculations detailed in the written module are also provided as an Excel solution file. A typical assignment is to predict the performance of an air-preheat system - air from the compressor, prior to the combustion chamber, is cross-heat exchanged with exhaust gas from the power turbine. This introduces the complication that the energy balance on the heat exchanger cannot be closed without results from the power turbine. We provide an Excel file for the air-preheat 
system which contains the needed conversion factors, some completed calculations, and a process diagram where calculation results are displayed. Student feedback on these incomplete modules has been positive (4.5/5.0, Fall 2009), and the structured format in the partial solution file makes it much faster to identify student problems. This module has been used as a group homework in ChE (4.4/5.0 overall satisfaction) and as a take home final exam problem in ME (4.6/5.0 overall satisfaction). The average solution time to complete the module is $4.2 \mathrm{hr}$.

Junior Year ( $1^{\text {st }}$ Semester): $\quad$ The Data Reconciliation (DR) module has been extensively used in $\mathrm{ChE}$ and ME junior labs at LSU, Tulane and FAMU-FSU. The DR module provides access to operational data from the cogeneration gas turbine and HRSG, and students are asked to determine reconciled values in Excel as,

$$
\begin{aligned}
& \text { Minimize }\left(\frac{\text { Measured Value }- \text { Reconciled Value }}{\text { Instrument Standard Deviation }}\right)^{2} \\
& \text { Subject to: Material and Energy Balances with Reconciled Values }=0
\end{aligned}
$$

The first time this DR module was used (Spring 2006), the average time to solve was $10.4 \mathrm{hr}$. When the statement "the problem promoted your understanding of the topic" was scored on a 0-5 scale an average of 4.3 was obtained. Utilizing student feedback, we now provide an Excel template (incomplete module) which writes measured and reconciled values on a figure embedded within the Excel file. Improved versions of the modules were utilized in Fall 2006, and the average solution time decreased to $5.9 \mathrm{hr}$. Most recently (2009), overall student satisfaction with the project was scored 4.8 in the Spring, and 4.9 in the Fall (0-5 scale). These are well above (by at least a full point) historical scores for a lab class at LSU. The experiment has been independently evaluated by the LSU Cain Center for STEM Literacy and student feedback shows that this module is considered the best of all the junior lab experiments and the one most representative of an assignment for a beginning engineer.

Junior Year ( $2^{\text {nd }}$ Semester): In the second undergraduate thermodynamics course in ChE we extend the ideal gas performance module (IGP) to real gas performance (RGP). Here real gas properties are used to predict the performance of the entire cogeneration system. These results are compared to actual operation and modeling results from commercial codes including GateCycle and IPSEpro. In the LSU module all the software is open equation, allowing students to see how a thermodynamics package is constructed, as well as opening up the possibility to add to or modify the code. The thermodynamic code is based on the work of W.R. Reynolds (1979) Thermodynamic Properties in SI. While most codes developed for educational use are indecipherable by, or inaccessible to, student users, the LSU physical properties package was specifically developed for both accuracy and ease of student use. The package is written in $\mathrm{C}++$ and assembled as a dll (dynamic link library). Access to all properties is intuitive; for example, the enthalpy of air, H_Air (T, P), is a function call in Excel. The same call can be used in a VBA, $\mathrm{C}++$, or other high-level language module.

Senior Year ( $1^{\text {st }}$ Semester): The heat recovery steam generator (HRSG) can be analyzed in both the ME Heat Transfer and ChE Unit Operations classes, using our heat transfer (HT) module. An HRSG is actually a complex heat exchanger system with multiple pinch points, if steam is 
generated at more than one pressure level. In the design case, the HRSG generates steam from the exhaust of the turbine without supplemental firing. However, there are many off-design cases, often presenting challenging analytical problems. In most off-design cases fuel is added to the exhaust from the turbine, and the mixture is fired, generating 3-4 times more steam than the unfired (design) case. We formulate two solutions to the off-design problems. Ganapathy's (1991) trial and error solution is easy to implement in Excel; this approach is applicable to HRSGs without radiant sections, or to a non-radiant portion of the HRSG. The more accurate solution is to model the heat exchangers using finite difference techniques using tube-level geometry, accounting for variable heat transfer coefficients and radiative losses. We provide the tube level geometry and the numerical methods subprograms, making this detailed analysis possible.

We developed another module that can be used in any of the courses cited above, or in Engineering Economics, or a first-semester design class. This module is based on levelized economics (LE), a common means of evaluating and comparing energy alternatives. Here costs (e.g., purchase of two different pumps) are brought to a present value basis, which is then converted to an annual cost and divided by the kilowatts used/generated. This gives an energy cost as $\$ / \mathrm{kW}$-hr for each alternative.

Senior Year ( $2^{\text {nd }}$ Semester): The optimal design (OD) module has been taught as part of the capstone design course; it is a natural continuation of either the IGP or RGP modules in which equipment and natural gas costs are added. The cost of each unit is represented using a power law expression, Cost Unit $_{i}=\alpha_{i}$ (Unit Perfromance Characteristic) $)^{\beta_{i}}$; here $\alpha_{i}, \beta_{i}$ are cost coefficients. A unit performance characteristic is, for example, for the air compressor, outlet to inlet pressure ratio. This module employs nonlinear optimization techniques to determine the cogeneration system design to best meet targeted electricity and steam needs. In Spring 2009, improved versions of the OD module were used with an average solution time of 6.8 hours and student satisfaction score of 4.65/5.0.

\section{$\underline{\text { Summary }}$}

We have developed six cogeneration modules which establish an energy thread throughout ChE and ME curricula of gradually increasing complexity and depth. These modules began with ideal-gas modeling of the LSU cogeneration system and later expanded to real-gas modeling, data reconciliation on the actual process, numerical solution of the heat-recovery unit performance, and, finally, optimal design of the entire system. 